\title{
Complutum
}

ISSN: 1131-6993

\section{La gestión de los recursos agropecuarios en la Oretania septentrional (siglos V-I} a.C.)

$\mathrm{M}^{\mathrm{a}}$ del Rosario García Huerta ${ }^{1}$; Fco. Javier Morales Hervás²; David Rodríguez González ${ }^{3}$ Lucia Soria Combadiera $^{4}$

Recibido: 24 de marzo de 2017 / 14 de noviembre de 2018

Resumen. Se presentan en este trabajo los resultados de los análisis antracológicos, carpológicos y faunísticos del yacimiento ibérico de Alarcos, a los que hay que sumar los faunísticos de Calatrava la Vieja y Villanueva de la Fuente, todos en Ciudad Real. A partir de éstos pretendemos reconstruir los sistemas de producción, transformación y consumo de productos agropecuarios, además de permitir una mayor aproximación al conocimiento del paisaje y el territorio de estos grupos.

Palabras clave: Producción agrícola y ganadera; paisaje.

\section{[en] The management of agricultural resources in northern Oretania (5th-1st centuries BC)}

Abstract. This work presents the results of the charcoal, carpological and faunistic analyses of the Iberian site of Alarcos and others of Calatrava la Vieja and Villanueva de la Fuente, all of them in Ciudad Real. Of these we aim to reconstruct the systems of production, transformation and consumption of agricultural and cattle products, and allow a greater approximation to the landscape and territorial knowledge of these groups.

Key words: Agricultural and cattle production; landscape.

Sumario: 1. Introducción. 2. El paisaje vegetal y la agricultura. 2.1 Los Cultivos. 2.2 Frutos Silvestres. 2.3. La explotación de otros recursos vegetales. 3. La transformación y conservación de alimentos. 3.1. La transformación de alimentos. 3.2. La conservación de alimentos. 4. Ganadería, caza y pesca. 4.1. La cabaña ganadera. 4.2. Caza y pesca. 4.3. La preparación de la carne y el uso de los recursos animales. 4.4. Otros recursos animales. 5. Conclusiones.

Cómo citar: García Huerta, Ma.R.; Morales Hervás, F.J.; Rodríguez González, D.; Soria Combadiera, L. (2018): La gestión de los recursos agropecuarios en la Oretania septentrional (siglos V-I a.C.). Complutum, 29(1): $151-170$.

\section{Introducción}

La organización económica de las comunidades iberas no ha sido una temática especialmente abordada en los estudios peninsulares hasta fechas recientes. Entre las primeras síntesis podemos citar las aportadas a la I Reunión de Historia de la Economía Antigua de la Península Ibérica, (Tarradell 1968). Será en los años 80 del siglo XX cuando una nueva línea de investigación, centrada en el análisis del territorio, promueva estudios interdisciplinares que aborden aspectos medioambientales en los que se implementan descripciones de los patrones de asentamiento, de estructuras de poblamiento y análisis de aspectos económicos (Ruiz y Molinos 1984; Miret et al. 1984; Bernabeu et al. 1987).

\footnotetext{
Dpto. de Historia, Universidad de Castilla-La Mancha. Avda. Camilo José Cela s/n. 13071 Ciudad Real. rosario.garcia@uclm.es

2 Dpto. de Historia, Universidad de Castilla-La Mancha. Avda. Camilo José Cela s/n. 13071 Ciudad Real. Fco.morales@uclm.es

3 Dpto. de Historia, Universidad de Castilla-La Mancha. Avda. Camilo José Cela s/n. 13071 Ciudad Real. david.rodriguez@uclm.es

4 Dpto. de Historia, Universidad de Castilla-La Mancha. Avda. Camilo José Cela s/n. 13071 Ciudad Real. lucia.soria@uclm.es
} 
Sin embargo, el verdadero avance se produce a finales del pasado siglo e inicios de éste con estudios centrados sobre productos concretos de un yacimiento o de un territorio (Ruiz y Molinos 1993; Gracia 1995; Alonso 1999; Pérez Jordá et al. 2000). Asimismo, en diversas Reuniones sobre Economía de los Iberos como las celebradas en Girona (AAVV 1999), Valencia (Mata y Pérez Jordà 2000; Mata et al. 2010) o Ciudad Real (García Huerta y Rodríguez 2009), se retoma el estudio de su estructura económica y se tratan nuevos temas como las prácticas alimentarias y se incorporan análisis de fauna, de semillas y de residuos orgánicos en contenedores de alimentos que aportan datos fundamentales para conocer los procesos de producción, transformación y consumo de productos agrarios, además de permitir una mayor aproximación al estudio de la dieta, la subsistencia y la relación con el territorio de estos grupos. En este contexto, las nuevas perspectivas sobre la producción y ex- plotación de recursos y las formas de organización de los procesos económicos y productivos de las comunidades ibéricas se conciben como el resultado de pautas de carácter cultural, que distinguen las estrategias económicas de las diferentes comunidades ibéricas.

Los estudios sobre economía en el Alto Guadiana adolecían, hasta hace pocos años, de la falta de analíticas que permitieran abordar este tema con el rigor necesario. Sin embargo, la calidad de los registros arqueológicos y los análisis realizados en diversos yacimientos nos permiten presentar ahora interesantes novedades partiendo tanto de los elementos materiales que indican actividades de almacenamiento, transformación y consumo en los yacimientos mejor documentados, como de los análisis realizados sobre diversas muestras del registro faunístico, carpológico y de contenidos, hemos realizado una nueva lectura que pretende ofrecer una panorámica general de las actividades económicas de los grupos oretanos septentrionales.

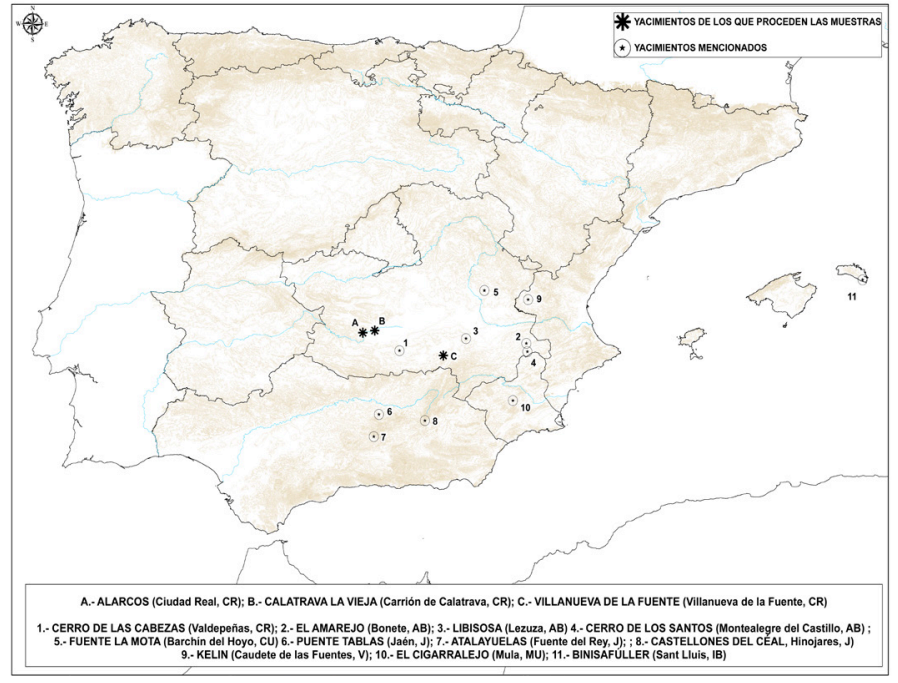

Figura 1. Localización de los principales yacimientos citados en el texto

\section{El paisaje vegetal y la agricultura}

Para afrontar este tema contamos esencialmente con los datos proporcionados por los análisis antracológicos y carpológicos realizados a partir de una serie de muestras recuperadas en el oppidum de Alarcos ${ }^{1}$, y los hallazgos de restos directos (carbones, restos de madera, semillas, etc.) e indirectos (estructuras destinadas a actividades relacionadas con la agricultura y la transformación de alimentos como almacenes y hornos, herramientas, análisis del paleopai- saje, etc.) de otros yacimientos de la Oretania septentrional.

Los estudios arqueobotánicos constituyen una valiosa fuente de información al permitir reconstruir el paisaje y el nivel de aprovechamiento de los recursos vegetales por parte de las poblaciones ibéricas. A partir de esos datos, se pueden hacer también inferencias de tipo climático o medioambiental y establecer cultivos y especies silvestres recolectadas, además de otras labores complementarias. Así, por ejemplo, la leña constituía un combustible impres- 
cindible para los hogares domésticos y una preciada materia prima para la elaboración de útiles. Su recogida supone un muestreo de la vegetación y ofrece una muestra representativa del entorno vegetal del yacimiento. En este sentido, conviene recordar que no es habitual talar árboles para la obtención de combustible, sino que se aprovecha la carrasca o los subproductos del árbol cuando se talan para obtener piezas de mayor tamaño para la construcción.

Los análisis antracológicos y carpológicos se han realizado a partir de muestras recogidas en el Sector III de Alarcos a lo largo de tres campañas de excavación, 2004, 2005 y 2010, y procedentes de diversos contextos arqueológicos: en primer lugar del almacén ibérico y, dentro de él, de un área específica como es el horno, en segundo lugar de áreas de habitaciones anteriores a la construcción del almacén y, por último, de la zona que rodea al almacén. El número de carbones recuperado ha resultado muy representativo, se han analizado un total de 4989 fragmentos que han permitido identificar un total de 52 especies

\begin{tabular}{|c|c|c|c|c|c|}
\hline \multicolumn{3}{|c|}{ ANÁLISIS ANTRACOLÓGICOS } & \multicolumn{3}{|c|}{ ANÁLISIS PALEOCARPOLÓGICOS } \\
\hline NOMBRE CIENTIFICO & $\mathrm{N}^{0}$ MUESTRAS & $\%$ & NOMBRE CIENTIFICO & $N^{0}$ MUESTRAS & $\%$ \\
\hline ACER SP. & 2 & 0.12 & AJUGA SP. & 6 & 0.32 \\
\hline ARBUSTUS UNEDO & 18 & 1.07 & CAREXSP. & 1 & 0.03 \\
\hline CISTUS SP. & 202 & 12.07 & FESTUCA TIPO. & 7 & 0.21 \\
\hline CF. CISTUS SP. & 9 & 0.07 & FICUS CARICA & 1 & 0.03 \\
\hline CONIFERAE & 4 & 0.24 & FOENICULUM VULGARE & 2 & 0.06 \\
\hline ERICA SP. & 12 & 0.72 & FUMARIA CAPREOLATAVAILANTIIIPARVIFLORA & 8 & 0.24 \\
\hline EUPHORBIA TP. DENDROIDES & 11 & 0.66 & GALIUM SP. & 4 & 0.12 \\
\hline FRAXINUS SP. & 123 & 7.25 & GLYCERIA DECLINATA & 2 & 0.06 \\
\hline JUNIPERUS SP. & 11 & 0.66 & HORDEUM VULGARE L. & 676 & 20.39 \\
\hline LABIATAE & 4 & 0.24 & HORDEUM SP. & 8 & 0.24 \\
\hline LEGUMINOSAE & 35 & 2.91 & HORDEUM FRAG. & 46 & 1.39 \\
\hline OLEA EUROPAEA & 4 & 0.24 & HORDEUM/TRITICUM FRAG. & 808 & 24.37 \\
\hline PINUS HALEPENSIS & 20 & 1.19 & LEGUMINOSAE & 2 & 0.06 \\
\hline PINUS TP. PINEA-PINASTER & 48 & 2.87 & LENS CULINARIS & 1 & 0.03 \\
\hline PINUS SP. & 16 & 0.96 & LOLIUM PERENNE/RIGIDUM & 3 & 0.09 \\
\hline PISTACIA LENTISCUS & 32 & 1.91 & LOLIUM FRAG. & 2 & 0.06 \\
\hline PÚNICA GRANATUM & 1 & 0.06 & MALVA SP. & 3 & 0.09 \\
\hline PRUNUS SP. & 98 & 5.85 & CF PISUM & 12 & 0.36 \\
\hline QUERCUS CADUCIFOLIO & 64 & 3.72 & POLYHONACEAE & 1 & 0.03 \\
\hline QUERCUS PERENNIFOLIO & 781 & 46.53 & POLYGONUM AVICULARE & 2 & 0.06 \\
\hline QUERCUS SP. & 27 & 1.60 & PRUNUS DULCIS & 7 & 0.21 \\
\hline RHAMNUS-PHILLYREA & 10 & 0.60 & PRUNUS DULCIS FRAG. & 8 & 0.24 \\
\hline CF. ROSACEAE & 1 & 0.06 & ROSACEAE FRAG. & 5 & 0.16 \\
\hline ROSMARINUS OFFICINALIS & 20 & 1.19 & SAMBUCUS NIGRA & 2 & 0.06 \\
\hline SALIX-POPULUS & 3 & 0.20 & SILENE CF. GALLICA & 1 & 0.03 \\
\hline SORBUS-CRATAEGUS & 6 & 0.34 & TRITICUM AESTIVUMIDURUM & 1308 & 39.44 \\
\hline CORTEZA & 7 & 0.40 & TRITICUM AESTIVUM TIPO COMPACTO & 205 & 6.18 \\
\hline \multirow[t]{5}{*}{ INDETERMINADO } & 105 & 6.27 & TRITICUM AEST/DURUM FRAG. & 150 & 4.52 \\
\hline & & & TRITICUM MONOCOCUMM & 19 & 0.56 \\
\hline & & & TRITICUM CF. MONOC FRAG. & 12 & 0.36 \\
\hline & & & VICIA FABA L. & 1 & 0.03 \\
\hline & & & VICIALAATHYRUS & 2 & 0.06 \\
\hline TOTAL & 1674 & 100 & TOTAL & 3315 & 100 \\
\hline
\end{tabular}

Figura 2. Especies vegetales documentadas en el Sector III de Alarcos, a partir de los análisis realizados por Guillem Pérez y Yolanda Carrión

Entre estos restos hay un amplio abanico de especies arbóreas y de matorral de diversos ambientes ecológicos. El mejor representado es Quercus, sobre todo la variedad perennifolia, que supera el $40 \%$, mientras que la caducifolia no llega al $4 \%$ del total. En cuanto a Quercus perennifolio no se ha podido diferenciar si se trata de la especie arbórea (encina, carrasca) o de la arbustiva (coscoja), dado que ambas comparten nichos ecológicos muy similares, si bien en otro sector del yacimiento si se ha identificado Quercus ilex (Fernández Rodríguez 2009: 231). El Quercus caducifolio en bajos porcentajes parece indicar bien la presencia de formaciones dispersas, entre las de perennifolios, o bien que formarían parte de la vegetación de ribera en zonas más húmedas cercanas a los ríos Guadiana y Jabalón, próximos al poblado.

Otras especies identificadas en porcentajes pequeños son Arbutus unedo (madroño), Prunus, Sorbus-Crataegus (majuelo). La aparición de Prunus sp., Prunus domestica y Prunus avium/cerasum indica la presencia del almendro, ciruelo y guindo/ cerezo en Alarcos. Las especies de ribera identificadas son Fraxinus y Salix-Populus y aunque resulta difícil identificar la especie, podría tratarse de $F$. excelsior o $F$. angustifolia. El matorral que constituye el 25\% del total ofrece una gran variedad de especies: 
Cistus sp., Erica sp., Labiatae, Leguminosae, Pistacia lentiscuens, Rosmarinus officinalis y Quercus coccifera. Los más representados son Cistus y Leguminosae, muy adaptados a la deforestación continuada, recolonizando rápidamente espacios de suelo empobrecido. La presencia de lentisco podría indicar un ambiente no excesivamente frío, ya que no tolera heladas prolongadas, si bien su baja representación (un fragmento) puede mostrar que se encuentra en el límite de su óptimo ecológico. Tampoco las coníferas ofrecen porcentajes importantes en el carbón de Alarcos (5 \%); hay al menos dos especies de pino (carrasco y piñonero) y los enebros/ sabinas. El más abundante es el pino piñonero, cerca de un 3\%, lo que resulta muy interesante a nivel paleoecológico, pues implica la existencia de afloramientos de tipo ácido o descarbonatado, sobre los que se desarrolla preferentemente esta especie (Costa et al. 1997).

A pesar de las limitaciones de los resultados antracológicos, el paisaje que muestra el carbón de Alarcos es un bosque esclerófilo mediterráneo dominado por Quercus perennifolio, salpicado de otras especies perennifolias (madroño) y un escaso, pero diversificado, grupo de especies de matorral. Las especies de ribera tienen una amplia representación, sobre todo el fresno, junto con los sauces-chopos. El fresno debió constituir la especie principal de las formaciones de ribera, debido posiblemente a una explotación dirigida hacia la puesta en cultivo de las llanuras aluviales, donde se localizarían fundamentalmente estos bosques de ribera. Las coníferas no debieron tener gran importancia, destaca el binomio Quercus-Fraxinus, a diferencia de otros análisis paleobotánicos realizados en la zona, como los realizados en del cerro de las Cabezas, donde predomina el binomio $\mathrm{Pi}$ nus-Quercus. En este mismo yacimiento los análisis polínicos han identificado la presencia del castaño, situado en las zonas umbrías de las laderas (Vélez et al. 2013: 134).

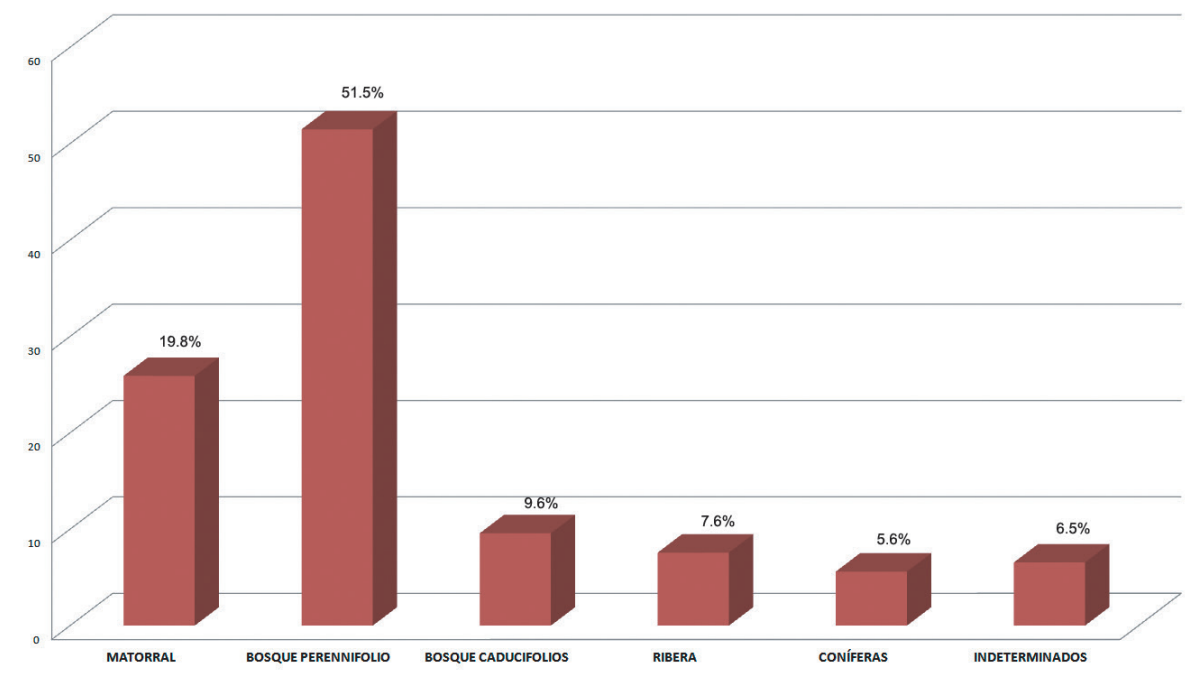

Figura 3. Porcentajes de las especies arbóreas

\subsection{Los Cultivos}

Los suelos cultivados por estas comunidades con mayor potencial agrícola son los terrenos sedimentarios de las comarcas de Campo de Calatrava, Campo de Montiel y La Mancha, donde se sitúan un gran número de yacimientos íberos. En la zona occidental de Ciudad Real, predominan los terrenos silíceos, poco aptos para el aprovechamiento agrícola, lo que podría explicar el menor número de asentamientos. Los datos sobre los cultivos proceden mayoritariamente del Sector III de Alarcos, siendo los cereales los mejor documentados, especialmente el trigo y la cebada. Del trigo se conocen dos variantes: Trigo desnudo (Triticum aestivum-durum) y trigo vestido (Triticum monoccocum y diccocum). Los cereales hallados proceden sobre todo del interior del almacén de grano, especialmente de la zona 
del horno de pan, donde aparecieron varias concentraciones de cereales, en las que había dos conjuntos formados mayoritariamente por trigos desnudos, tanto de formas laxas como de compactas. También se han recuperado restos de cebada, así como dos fragmentos de cáscaras de almendras. En todos los casos se trata de conjuntos muy limpios, sin restos de desechos de trilla ni de malas hierbas, lo que parece indicar que se han sometido a un proceso de limpieza exhaustivo (trillado, descascarillado, aventado y cribado) y están dispuestos para el consumo. De lo que parece deducirse que el almacén se dedicaba a conservar y procesar dos tipos de cereales: trigo, fundamentalmente desnudo y, en menor medida, cebada vestida, junto a una escasa representación de trigos vestidos. En el edificio tripartito de Alarcos, dos de los recintos dedicados al almacenamiento y procesado repiten los mismos tipos y porcentajes (Fernández Rodríguez 2009:231). Las muestras analizadas en el cerro de las Cabezas también proceden de un almacén, Q1B, y han aportado un 97,6\% de cereales (Vélez et al. 2013:125), aunque únicamente está representada la cebada vestida, lo que parece indicar que este almacén se dedicaba exclusivamente a este cereal.

Las muestras del Sector III de Alarcos obtenidas fuera del almacén presentan algunas diferencias respecto a las recuperadas en aquel. En ellas se encuentran algunas especies silvestres, consideradas como malas hierbas en los campos de cereales y, entre éstas, hay especies que producen semillas de tamaño fino, que generalmente se separan de los cereales en la última fase del cribado. Esto permite inferir que el grano llegaría al poblado prácticamente limpio, aunque es probable que aquí, antes de su procesado, se hiciera un cribado fino para eliminar las últimas impurezas, que podrían utilizarse como combustible o como alimento para las aves de corral. Aunque los cereales son el grupo más numeroso, en ningún caso se trata de altas concentraciones; también aparecen almendras y guijas y, como especies silvestres, la Glyceria declinata y las Festucas, que se desarrollan en charcas semipermanentes, lagunas y arroyos de curso lento, formando parte de herbazales de lugares inundados y otras especies típicas de ambientes más secos como el Galium (galio) y la Malva sylvestris (malva).

El conjunto de especies silvestres no es muy elevado y parece indicar que hay zonas dedicadas al cultivo de cereal en áreas bajas, cerca del río, donde parte de estos campos se inundarían en determinadas épocas del año, con el consiguiente incremento de los nutrientes en el terreno cultivable. Por tanto, las zonas ubicadas en la vega del río se podrían utilizar para cultivar cereales y posiblemente leguminosas, ya que serían las más ricas y presentarían unos suelos más profundos. No obstante, es evidente que también se utilizaron para el cultivo campos más o menos cercanos al asentamiento, donde se desarrollaría una agricultura de carácter extensivo.

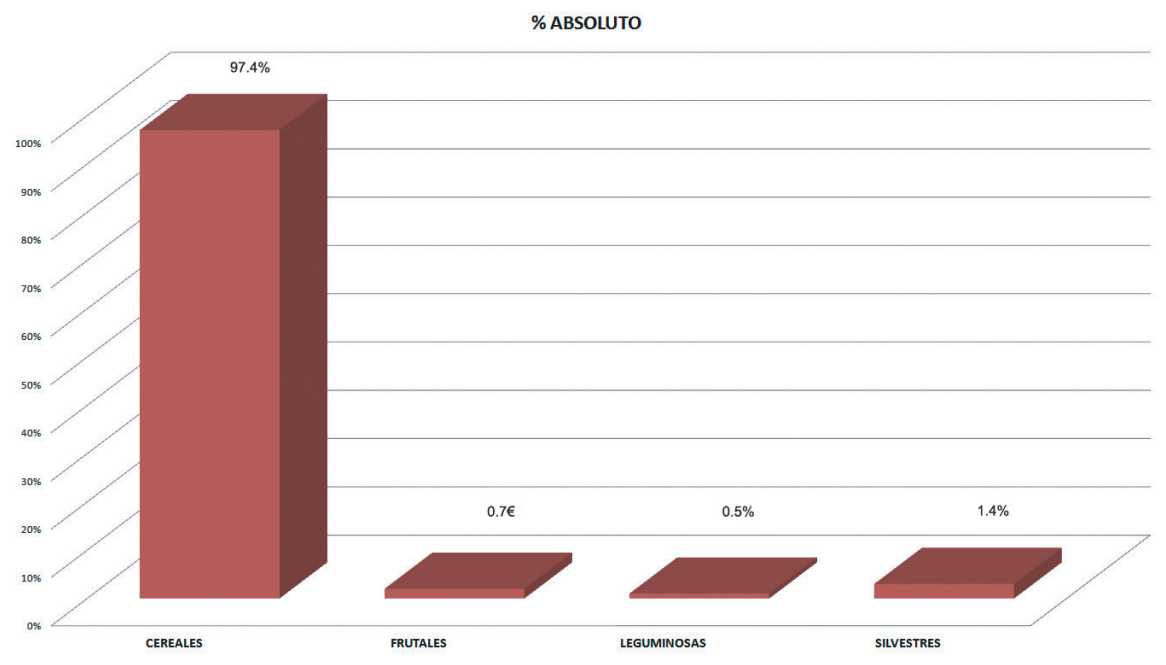

Figura 4. Gráfico de las especies cultivadas 
El segundo grupo de cultivos en el Sector III son los frutales, representados por almendras (Prunus dulcis) y también por fragmentos de huesos de rosáceas que podrían ser ciruelos o guindos/cerezos (Prunus avium/cerasus), identificados también en otros lugares de Alarcos, aunque no hay certeza de que se trate de una especie cultivada. Otros frutales encontrados en este Sector son el granado (Punica granatum) y la higuera (Ficus cárica). Estos frutales, con la excepción del almendro, no suelen aparecer en el registro arqueológico de los núcleos de habitación ibéricos,y solo conocemos ciruelos, almendros e higos en El Amarejo, (Mata et al. 2010:35; Broncano 1989:5859). La granada aparece de forma figurada pintada en un jarro del Departamento 4 del mismo yacimiento y de forma real en uno de sus depósitos votivos (Broncano y Blánquez 1985:240-241).

Uno de los cultivos más característico del ámbito mediterráneo, el olivo, no está claramente documentado en Alarcos. Se han identificado restos de Olea Europaea, pero la gran similitud entre la variedad cultivada (olivo) y la silvestre (acebuche), no permite asegurar que sea olivo, como sucede en otros yacimientos ibéricos de áreas próximas como en El Amarejo (Broncano 1989: 59). En lo referente al cultivo de la vid, debemos señalar que en el oppidum de Alarcos, a pesar del gran número de muestras recuperadas en el Sector III, no se ha detectado ningún resto que avale el cultivo de la vid, si bien en el edificio tripartito (Fernández Rodríguez 2009: 232) se encontraron cinco pepitas de vitis vinífera, muestra ciertamente escasa si tenemos en cuenta las más de 1.700 muestras analizadas, lo que nos lleva a pensar que en Alarcos no debía estar muy extendido su cultivo, o bien, que su procesamiento se llevaba a cabo en zonas diferenciadas dentro del oppidum. En el cerro de Las Cabezas apareció vitis sp en niveles del Ibérico Pleno, en una habitación adosada a un almacén que se dedicaría, según sus investigadores, a almacenar cereales y vino (Vélez et al. 2013: 144). En este sentido, no podemos descartar la existencia de una cierta especialización por parte de algunos asentamientos en el cultivo y procesamiento de determinados productos.

Junto a cereales y frutales se documenta el cultivo de leguminosas que, por la información procedente de otras áreas estudiadas, están menos representadas que los cereales. Los datos procedentes de nuestros trabajos de campo van en idéntica dirección, al ocupar las leguminosas el tercer lugar en importancia dentro de los cultivos, aunque en el edificio tripartito se sitúan en segundo lugar. Este hecho se suele explicar por cuestiones taxonómicas, ya que durante su procesado no necesitan tener un contacto directo con el fuego, sin embargo los frutales tampoco lo tienen y en nuestro caso su presencia es más destacada, lo que indica que las leguminosas tendrían menor peso que los otros dos grupos de especies cultivadas en la agricultura ibérica, al menos con seguridad en el caso de los cereales. En Alarcos la leguminosa más documentada es la lenteja (Lens culinaris), seguida del haba (Vicia faba L.); menor representación tienen el guisante (Vicia $s p$. o pisum), la guija (vicia /latyrus) y el yero (Vicia ervilia), especie muy similar a la algarroba que solía destinarse al ganado. En el oppidum del cerro de Las Cabezas se ha encontrado veza (Vicia sativa), utilizada habitualmente como forraje, aunque no se tiene la certeza de si se trata de la especie silvestre o de la cultivada (Vélez et al. 2013:127). Las leguminosas requieren un aporte hídrico más regular que el cereal, pero se adaptan bien a períodos secos, y es probable que se cultivaran en zonas próximas al área de hábitat, posiblemente recolectadas entre cosecha y cosecha de cereales. En El Amarejo y Barchin del Hoyo también hay evidencias de cultivo de habas y guisantes (Broncano 1989: 58).

\subsection{Frutos Silvestres}

Entre los frutos silvestres producto de una actividad recolectora documentados en el Sector III de Alarcos están las bellotas y los piñones. El hallazgo de un fragmento de cotiledón de bellota, unido a la presencia de carbones de Quercus ilex, parece confirmar su recolección y posterior uso. Este fruto está muy bien documentado entre las poblaciones prerromanas como complemento alimenticio, prepara elaborar tortas. Autores clásicos como Estrabón y Plinio aluden al consumo de pan de bellota por parte de los celtíberos y en el ámbito ibérico son numerosos los yacimientos en los que aparecen bellotas (Pereira 2010). Por lo que respecta a los piñones no hay evidencia directa de su recolección, pero la presencia de pino piñonero, invita a pensar en el aprovechamiento de este recurso.

La lectura conjunta de los diferentes cultivos del Sector III de Alarcos muestra el pre- 
dominio de los cereales que, como ya constatamos en un trabajo anterior, alcanzaban entre el $97 \%$ y el $62,6 \%$ (García Huerta y Morales 2009: 181). Los nuevos análisis confirman estos datos. Entre los cereales, predominan los trigos desnudos (Triticum aestivum/durum), $40 \%$, seguidos por la cebada vestida (Hordeum vulgare L.). También hay trigos vestidos, pero en porcentajes muy bajos, confirmando que se trata de un cultivo poco extendido en época ibérica y que siempre ocupa un papel muy secundario respecto a los otros cereales lo que, en algunos casos, podría indicar una opción para cultivar terrenos con suelos más pobres, al adaptarse mejor a ellos que los trigos desnudos. Hay estudios etnográficos que muestran cómo el cultivo de la escaña, en ocasiones, está condicionado, más que por el aprovechamiento de sus semillas, por el tipo de paja que produce (Peña-Chocarro y Zapata 2000), más larga y resistente, por lo que es frecuente su uso como material constructivo o para elaborar camas, etc. Y no podemos olvidar que la paja de cereal constituye un subproducto de gran importancia que se sigue utilizando en la construcción para los techos de viviendas de tipo tradicional, así como para la elaboración del adobe.

Todo parece indicar la existencia de una agricultura cerealista de carácter extensivo desarrollada en campos de cultivo más o menos cercanos a los asentamientos y una agricultura, a menor escala, desarrollada en huertos junto a las vegas de los ríos, como indica la aparición de especies silvestres, que crecen como malas hierbas en suelos característicos de este medio. Para los frutales se dedicarían suelos más pedregosos o con mayor pendiente, pues se trata de especies menos exigentes en la calidad edáfica, al igual que la cebada vestida, presente entre los cultivos que se adaptan a todo tipo de terrenos y a condiciones climáticas desfavorables, con rendimientos altos.

Los cereales, en general, son cultivos de invierno, aunque algunas variedades también se pueden cultivar en primavera. La siega se realizaría con hoces y también se utilizarían otros instrumentos como podaderas, legones, azadas, molinos y morteros de piedra. La limpieza del cereal para separar el grano de la paja se realizaría en los propios campos, realizando solo la última fase de cribado fino en el poblado, y después se procesaría o se almacenaría, como muestran el gran número de almacenes documentados en los distintos yacimientos ibéricos que hemos analizado (García Huerta y Morales 2009).

\subsection{La explotación de otros recursos vege- tales}

Los análisis realizados a partir de los restos de carbón recuperados en Alarcos ha permitido identificar el tipo de madera, su procedencia y, hasta cierto punto, sus diversos usos. Así, entre los carbones recogidos en el horno del Sector III hay 15 taxones, con predominio de carrasca y jara, especies muy adecuadas para obtener un fuego rápido y una llama viva. Los árboles de ribera, especialmente el fresno, así como sauces y chopos están bien representados. El roble presenta porcentajes altos en una de las habitaciones de inicios del primer milenio, como consecuencia de haberse utilizado posiblemente en la construcción de ese recinto. En el edificio tripartito, que sufrió un incendio, parece que encinas y pinos se usarían en los postes que sostendrían un techo formado con un enramado de jara, ramas de fresno, lentisco, guindo-cerezo y sauce (Fernández Rodríguez 2009:230).

El resultado de los análisis señala que las necesidades de combustible en Alarcos se cubrirían con leña procedente de las formaciones vegetales próximas al poblado: Quercus, especialmente perennifolio, acompañado de madroño y un gran número de especies de matorral, aunque en porcentajes bajos. Este resultado concuerda perfectamente con las características energéticas de las especies de crecimiento lento, que presentan mayor densidad $\mathrm{y}$, en consecuencia, mayor poder calorífico que aquellas otras de crecimiento rápido que arden con facilidad y se consumen rápidamente. Las especies de ribera tienen altos porcentajes, destacando el fresno, mientras que las coníferas tienen poca importancia.

\section{La transformación y conservación de alimentos}

La transformación de los productos agrícolas ya fue objeto de un trabajo anterior (García Huerta y Morales 2009) en el que analizamos las estructuras de almacenamiento, fundamentalmente de cereales, entre los pueblos prerromanos de la meseta meridional y abordamos de manera colateral la producción de alimentos, centrándonos en los procesos seguidos para el tratamiento de los productos almacenados. La documentación arqueológica aportaba datos sobre la molienda, el tostado y la cocción de cereales. Más complejo 
resulta detectar a través del registro arqueológico la existencia de otros procesos de conservación como el ahumado o la salazón de carnes y pescados, cuya práctica debió ser algo habitual entre estas poblaciones, sobre todo si tenemos en cuenta que en la meseta meridional existen importantes áreas de aprovisionamiento de sal, aspecto que abordamos en otro apartado de este trabajo.

\subsection{La transformación de alimentos}

La realización de análisis de contenidos de un conjunto de materiales cerámicos procedentes del oppidum y de la necrópolis de Alarcos $^{2}$ nos permite ampliar el conocimiento que teníamos sobre la producción y transformación de alimentos. Los resultados obtenidos indican la presencia de contenidos en 7 de los 9 recipientes analizados, lo que según los autores de estos análisis es un porcentaje positivo, poco habitual. De los 7 recipientes, cuatro de ellos muestran un perfil graso y/o de cera bien definido; en el resto la conservación de indicadores es más parcial, sólo el empleo de HPLCAPCI-MS ha permitido la identificación de triglicéridos conducentes a la propuesta de contenidos.

\begin{tabular}{||lll||}
\hline \hline \multicolumn{1}{|c|}{ RECIPIENTE } & \multicolumn{1}{c}{ CONTENIDO } & DENIFICIÓN \\
AL/10- U15-9-1 & Cera de abeja & Buena \\
AL/10- U15-9-2 & Grasa vegetal + grasa animal rumiante (¿Posible leche?) & Buena \\
AL/10- U7/8 MS5 & Grasa de animal rumiante + residuos de cera de abeja & Buena \\
AL/10- U7/8 MS4 & Grasa vegetal & Baja \\
NE AL/14 TUMBA 10-M1 & Grasa de animal rumiante + residuos de grasa vegetal & Buena \\
NE AL/14-TUMBA 10-M2 & Grasa vegetal + residuos de grasa animal & Baja \\
NE AL/14-TUMBA 11 & Residuos de grasa vegetal & Baja \\
\hline \hline
\end{tabular}

Figura 5. Muestras analizadas de Alarcos: contenido y definición de Alarcos

El conjunto de indicadores químicos está asociado a la presencia de diferentes contenidos, aislados o formando mezclas. No se puede precisar si las combinaciones de contenidos son debidas a diferentes usos del recipiente o a un único evento en el que participaron los dos productos identificados. En el estudio se han identificado tres tipos de productos: cera de abeja, grasas de origen animal y grasas de origen vegetal. La cera de abeja se ha identificado en una zona situada junto al almacén de grano, donde había un horno; se trata de un área de carácter comunal dedicada a la transformación de alimentos, al menos de cereales, por lo que podría haberse utilizado para la iluminación, ya que la cantidad conservada es bastante importante y parece indicar este uso. En cuatro muestras se han identificado grasas de origen animal, que podría corresponder a diversas especies de rumiante: bovino, caprino, ovino y cérvido. Las investigaciones realizadas por el equipo del Instituto de Arqueología Ibérica de Jaén en Puente Tablas (Jaén) y en el santuario de Atalayuelas (Fuente del Rey, Jaén) determinaron también la presencia de grasa procedente de rumiantes. En el caso de nuestro recipiente AL10/U15-9-2 se han detectado ácidos grasos volátiles en su perfil lipídico (cáprico, láurico, mirístico), lo que permite a estos investigadores plantear que podría tratarse de una grasa láctea de ese tipo de animales, es decir, leche de rumiante.

La grasa de origen vegetal sería el tercer producto identificado de forma inequívoca debido al conjunto de TAGs insaturados detectados. La susceptibilidad de estos compuestos para degradarse por oxidación repercute en una pérdida de información relevante relacionada con el origen de la grasa o aceite de la que proceden. Se han encontrado restos de grasa vegetal en cinco de las siete muestras analizadas, en dos casos como único resto y en otras tres asociados a grasa animal.

Los autores de estos análisis no identifican claramente el origen de esta grasa vegetal, pero plantean que los estudios antracológicos y carpológicos pueden proporcionar datos sobre las especies oleaginosas de la zona de las que extraer este producto. En este sentido, las especies vegetales más abundantes en el entorno del yacimiento, susceptibles de aportar grasa vegetal, son principalmente la aceituna (de acebuche u olivo) y los frutos secos. Mientras que la obtención de aceite a partir de la aceituna puede realizarse por métodos de presión muy artesanales, para los frutos secos sería necesario el uso de un molino rotatorio. Con este molino se genera una masa oleaginosa a partir de la cual, y ejerciendo presión con las manos, se obtienen pequeñas cantidades de aceite. La 
actual producción artesanal de aceite del fruto seco llamado argán en Marruecos constituye el mejor ejemplo de este sistema de trabajo (Charrouf y Guillaume 2008; López y Alba 2009). La cocción de los frutos secos podría incluirse como una segunda opción que podría liberar grasa vegetal que se fijaría al recipiente, aunque probablemente en baja proporción.

Como hemos señalado, los análisis antracológicos y carpológicos reflejan la presencia de acebuche u olivo y de almendro, y el registro arqueológico documenta el instrumental para la obtención de su aceite. Concretamente en la zona de Alarcos de donde proceden las muestras, se han hallado un gran número de molinos rotatorios (Rodríguez y López-Menchero 2009), por lo que la grasa vegetal, el aceite, podría proceder de uno o de ambos frutos, que, junto al consumo doméstico también podría ser empleado en el ámbito medicinal, cosmético y ritual, uso este último que deducimos a partir de su presencia en vasos de la necrópolis de Alarcos.

\subsection{La conservación de alimentos}

Las técnicas para la conservación de alimentos durante la Antigüedad tuvieron una gran importancia para garantizar la disponibilidad, y por tanto el consumo, de productos de temporada durante más tiempo al paralizar o retrasar la acción de los microbios y otros agentes responsables del deterioro de los alimentos. Los procedimientos de conservación que conocemos en el área de estudio fueron diversos y consistieron, sobre todo, en el almacenamiento de productos en grandes contenedores cerámicos (ánforas y tinajas) cubiertos con tapaderas o platos-tapadera. También se usaron cestos y capazos de esparto para los productos frescos o de temporada, como revelan los hallazgos de esparto en uno de los almacenes comunales del cerro de Las Cabezas (Vélez et al. 2013:137). Fuera del territorio oretano otros hallazgos son los del pecio de Binisafúller (Menorca) (Aguelo et al. 2008) o los de El Cigarralejo (Mula, Murcia) (Cuadrado 1987:102-103). Para poder conservarlos durante periodos prolongados de tiempo, especialmente los frutos, el procedimiento más habitual y sencillo es el secado (setas y uvas, por ejemplo), o almacenamiento en lugares protegidos de la humedad y separando unas piezas de otras (manzanas).

En las viviendas, son los grandes contenedores los indicadores de las áreas destinadas al almacenamiento doméstico o despensas. Se dispondrían sobre el suelo o sobre bases anilladas y se protegerían con tapaderas cerámicas o platos para preservar los productos destinados al autoconsumo, como ocurre en Libisosa (Uroz et al. 2007). Además de estos almacenes de carácter unifamiliar, se conocen almacenes comunales, de grandes dimensiones y formas diversas, como los de Alarcos y Cerro de las Cabezas. El de Alarcos, es un edificio rectangular del que no conocemos todavía su planta completa, pero que tiene una superficie superior a los $400 \mathrm{~m} 2$ y una capacidad de almacenamiento de más de $1000 \mathrm{~m}^{3}$, que corresponderían a unos $750.000 \mathrm{~kg}$ de trigo (García Huerta y Morales 2009:195). En el Cerro de las Cabezas son dos los almacenes comunales para cereales localizados en la muralla sur, ambos de planta rectangular y superficies similares $(6 \times 5 \mathrm{~m}$ y $6,5 \times 3,25 \mathrm{~m})$ aunque el primero es sobreelevado (Vélez et al. 2013).

Como ya se ha mencionado, otra técnica de conservación de alimentos que emplearon los iberos fue la salazón (Chapa y Mayoral 2007: 143-144). La sal ha sido un producto muy empleado por las sociedades protohistóricas por su variada utilidad. Además de ser un ingrediente en la elaboración de guisos, es complemento alimenticio indispensable para el ganado, y permite la conservación de alimentos perecederos, sobre todo carnes y pescados. Columela (De re Rustica XII, capítulo IV) y Estrabón (III, 4, 11) mencionan su uso por parte de iberos y galos en la preparación de la carne para su conservación. Este recurso fue también empleado para el curtido de pieles (Columela, De re Rustica, VII) e incluso en la medicina tradicional (Plinio, Naturalis Historia, XXXI, 86). Las primeras evidencias de la explotación e intercambio de sal en la península ibérica se remontan al Neolítico, como muestra el estudio de salinas y afloramientos de sal gema y los restos fermentados de algunas vasijas del área catalana (Fíguls et al. 2013: 178-179). Para la Edad del Hierro apenas contamos con referencias sobre la existencia y explotación de este recurso, con la excepción de las famosas salazones de pescado del círculo del Estrecho (Vallejo et al. 1999; Alonso et al. 2003) y las explotaciones de las salinas del litoral alicantino e interiores, como las de Villena (Vilá Valentí 1955). El aprovechamiento de la sal en áreas de interior es aún menos conocido, con algunas excepciones correspondientes al área celtibérica (Cerdeño y Pérez 1992). 
En el área más oriental de la Oretania septentrional, donde existe una gran cantidad de lagunas y navas o navajos, importantísimo recurso para el tránsito del ganado, se localiza el principal lugar de explotación de sal. En en el sector Este de la comarca del Campo de Montiel, en el territorio de Libisosa, se ubican las salinas de Pinilla a poco más de $25 \mathrm{Km}$ al suroeste del oppidum. Aunque no es hasta el siglo XV cuando la mencionan las fuentes documentales (Ladero Quesada 1987: 831), seguramente estuvieron en uso durante la Protohistoria. En el resto del territorio oretano no se conocen otras explotaciones mineras de sal o salinas, sin embargo, existen diversas zonas donde pudo explotarse este recurso. La geología de la zona y las referencias toponímicas a la existencia de sal, en estrecha relación con lagunas que presentan notable o alta concentración de sal, permiten sugerirlo. En las cuencas de los ríos Cigüela y Záncara existen suelos salinos relacionados con los sedimentos arcillosos mesozoicos, las lagunas, la llanura de inundación y los movimientos de aguas superficiales (García Rodríguez y Pérez González 2007: 55, 57). La topografía incide en el desarrollo de los suelos dificultando el lavado de las sales cuando se localizan en áreas deprimidas, por lo que se acumulan con frecuencia en superficie, produciendo costras de sal que pueden alcanzar los $10 \mathrm{~cm}$ de espesor cuando se hallan expuestos a una desecación estival. En los términos municipales de Campo de Criptana, Pedro Muñoz y Alcázar de San Juan existen varias lagunas y humedales estacionales de carácter salino, que al evaporarse en verano favorecen la formación de depósitos de sales (Carricondo et al. 2008: 33-34). Estas afloraciones salinas pudieron ser explotadas por las poblaciones oretanas del entorno, donde se localizan diversos yacimientos.

\section{Ganadería, caza y pesca}

Diversas fuentes clásicas inciden en la arraigada vocación ganadera de las poblaciones prerromanas meseteñas (Salinas de Frías 198687: 28), realidad que queda corroborada por la cantidad de animales documentados en los yacimientos protohistóricos de la zona. Sin embargo, a pesar de las abundantes muestras de animales domésticos consumidos en todo contexto arqueológico, las comunidades íberas no basaban su economía y su alimentación en los animales. De hecho, ninguna sociedad agropecuaria utiliza el ganado como base de su dieta alimenticia, puesto que el sacrificio de individuos para su consumo habitual provocaría el colapso del rebaño. En este mismo sentido, investigadores como Chapa y Mayoral (2007: 69) señalan que una economía predominantemente ganadera sería imposible, puesto que una familia tipo, de unas cinco o seis personas, debería sacrificar más de un centenar de animales al año para alimentarse, algo inasumible para una unidad familiar prerromana. Por tanto, se colige, como ya hemos indicado, que el rebaño no se constituye en la fuente preferente de alimento sino que juega otro papel en la estructura social y económica de estas comunidades. En consecuencia, podemos afirmar que la ganadería no era la actividad fundamental pero era importante tanto por cuestiones alimenticias, por los productos secundarios que aportaba y la ayuda en el laboreo, y por supuesto por su alto valor simbólico tanto desde el punto de vista religioso como del status social.

\subsection{La cabaña ganadera}

Para realizar una aproximación a las características de la cabaña ganadera, en el ámbito de estudio, contamos con análisis faunísticos procedentes de tres de los asentamientos más relevantes del área: Alarcos (Ciudad Real), del cual se han analizado más de 10529 restos, Villanueva de la Fuente que aporta 1088 restos y Calatrava la Vieja (Carrión de Calatrava) del que hemos estudiado 81 huesos. ${ }^{3}$

En Alarcos, a partir de los restos de fauna exhumados en las campañas de 1997 a 2006 y de 2009 a 2013, se han detectado hasta nueve especies domésticas: Bos taurus, Ovis aries, Ovis-Capra o Capra hircus, Sus domesticus, Equus caballus, Equus asinus africanus, Gallus gallus y Canis familiaris. Se ha podido determinar a qué especies pertenecían el 78,6\% de los restos. Un factor importante que explica el alto porcentaje de identificación es la escasa fragmentación del conjunto óseo, dado que parte del material estudiado sobrepasa los $3 \mathrm{~cm}$ de longitud. Los ovicápridos son los más abundantes tanto en el NR como en el NMI de todo el conjunto, les siguen los bóvidos y a continuación los suidos. Por su parte, el perro, el caballo, el burro, la gallina también están representados dentro del grupo de especies domésticas, pero en porcentajes muy reducidos respecto a las tres especies mayoritarias. 


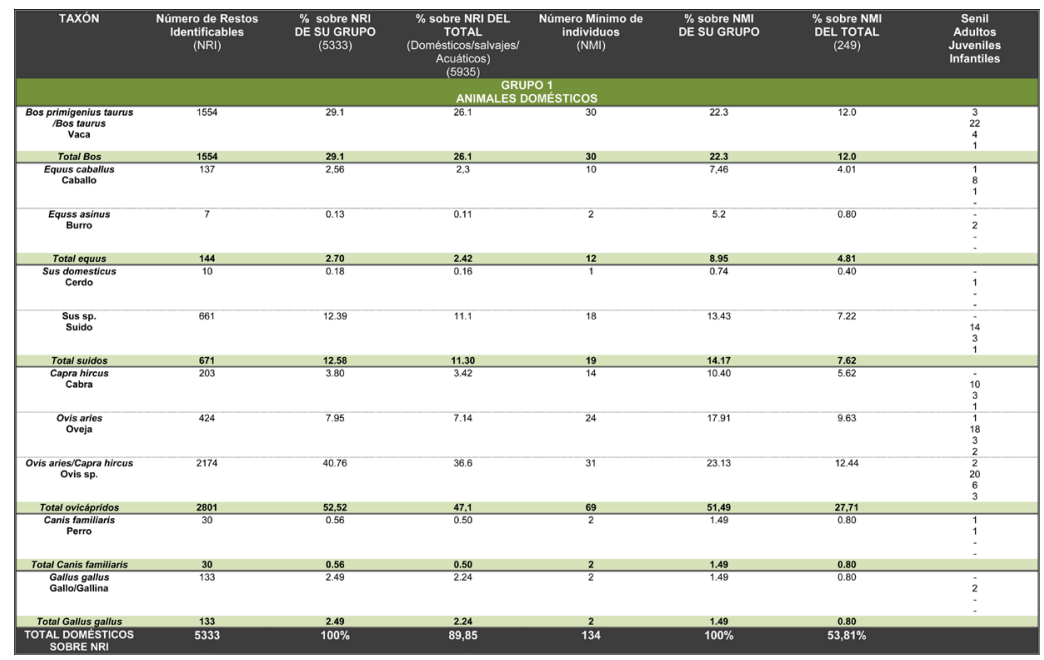

Figura 6. Animales domésticos

En comparación con informaciones procedentes de estudios mucho más amplios realizados en otros territorios, como el valenciano (Iborra 2004: 389), o la zona del Valle del Guadalquivir (Iborra 2000: 83) se advierten las mismas constantes: el porcentaje de animales domésticos frente a los salvajes suele ser de 9 a 1. De la misma manera, también se corrobora que las especies domésticas más comunes y por ese orden son Ovis aries, Ovis/ Capra (47,1\% del total de NRI), Bos Taurus $(26,1 \%) y$, en menor medida, Sus sp. o domesticus (11,30\%) y Equus caballus/asinus $(2,42 \%)$. Respecto al cerdo hemos de hacer una precisión: se ha detectado cerdo doméstico (un ejemplar como NMI) perteneciendo los otros restos a la categoría general de Suido sp., habiendo optado por incluirlos dentro del grupo doméstico puesto que por el ambiente en el que se encontraron - y teniendo en cuenta la escasa representación de Sus scropha en el conjunto de los enclaves íberos peninsularestodo parece apuntar a que la mayoría de suidos son parte de la cabaña ganadera. Además están representados en un porcentaje similar al de muchos otros yacimientos del mismo período, (Ibídem 2004: 389-393), ratificándose en Alarcos que la proporción de cerdo suele estar algo por debajo de la de bóvido.

Estos datos también se corroboran al compararlos con los del resto de enclaves oretanos analizados. Aunque el número de registros estudiados sea menor, muestran el predominio de la especie Ovis aries, Ovis/Capra, puesto que en el cerro de las Cabezas el $46 \%$ de los animales domésticos detectados, seguidos por bóvidos (25\%), suidos (14\%) y équidos $(5,8 \%)$
(Esteban et al. 2003: 28-35), datos similares a los de Calatrava la Vieja, con un $50 \%$ ovicápridos y un $16,8 \%$ de bóvidos, no habiéndose detectado suidos, seguramente por el reducido número de huesos estudiados. En el caso de Villanueva, los datos son igualmente similares pero presentan la particularidad de que el suido está algo más representado que el bóvido, estando su ganadería compuesta por un $33,3 \%$ de ovicápridos, $15 \%$ de suidos, $12,5 \%$ bóvidos y un $12,5 \%$ de équidos. En definitiva, es evidente que la ganadería era una actividad muy importante para la economía íbera. Sería frecuente ver rebaños de ovejas y cabras ramoneando tras la siega, piaras de cerdos en las zonas aledañas a los poblados, incluso dentro del espacio doméstico, completando la cabaña los bóvidos, que además de carne, aportan productos derivados como la leche y fuerza de tiro.

Por último, hay que destacar la importancia de estos animales en el aspecto cultual: en la Meseta Sur se documenta la aparición de representaciones de animales domésticos, bien como exvotos o en relieves o esculturas procedentes de necrópolis y santuarios. Hay más de una treintena de estas representaciones (Mata et al. 2014), siendo el caballo el animal más representado con una veintena de imágenes, procedentes sobre todo del Cerro de los Santos (Montealegre del Castillo, Albacete). También en Alarcos (Blánquez 1995: 49) apareció en un contexto doméstico un exvoto que representa a un caballo. El siguiente tipo de animal más usado en contextos religiosos es el bóvido con nueve ejemplares, completando el elenco algún tipo de ave indeterminada (Mata et al. 2014). La relevancia de los animales en el ám- 
bito de las creencias también está atestiguada a partir de sacrificios como los que se documentan en el depósito votivo del Amarejo, donde se localizaron ovicápridos (Iborra 2004: 335) y perro (Broncano 1989).

\subsection{Caza y pesca}

La actividad cinegética constituye una constante entre los grupos humanos desde los primeros momentos de su desarrollo tanto por su valor energético como por el papel social que sin duda desempeña. Desde el punto de vista de la dieta, la caza sería un complemento alimenticio para estas comunidades, sin olvidar su papel como fuente de materias primas. En Alarcos los animales salvajes apenas suponen un $10 \%$ del total -solo un $6 \%$ si excluimos a los animales acuáticos-, destacando los conejos o liebres (Oryctolagus cuniculus y Lepus europaeus), 200 restos, 4,04\% del total, y los ciervos (Cervus elaphus) con algo menos de 100 restos $(1,95 \%)$. De lejos, siguen el lobo (Canis lupus), la perdiz (Alectoris rufa) y el gato montés (Felix $s p$ ), animales de los que he- mos detectado tan solo un ejemplar, así como probablemente algún jabalí (Sus scrofa), especie que resulta difícil de identificar por su similitud con el cerdo doméstico. Lo mismo sucede con un posible ejemplar de zorro ( $\mathrm{Vul}$ pes vulpes), pues su diferenciación respecto al lobo es complicada debido al registro óseo en cuestión. El yacimiento de Villanueva de la Fuente aporta otro animal que solo aparece en este enclave, el corzo (Capreolus capreolus) registrándose un único ejemplar.

Así, la caza del ciervo parece ser una constante en todo el ámbito ibérico (Pérez Jordà et al. 2007: 363), habiendo aparecido en todos los enclaves que analizamos. Los estudios generales certifican los datos de la Oretania, con el predominio de las liebres, del ciervo, y el lobo, posiblemente cazado para defender a los rebaños de su ataque. El último tipo de animal que aparece en nuestros registros es el lagarto común (quizá Lacerta lepida o Timon lepidus), que aunque no podemos catalogarlo como especie derivada de las actividades cinegéticas, la incluimos puesto que solo se ha registrado en nuestra zona.

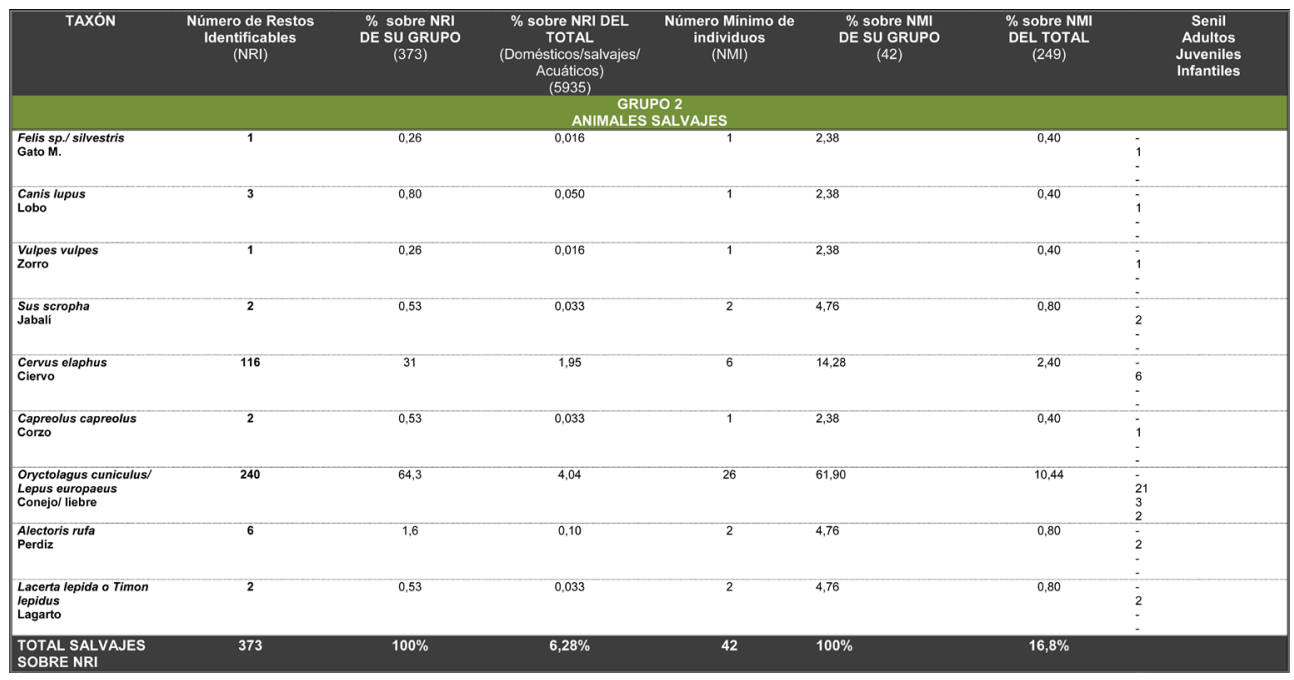

Figura 7. Animales salvajes

Sobre la pesca, normalmente con trasmallo, esparavel o tarraya está atestiguada en el Guadiana (zona extremeña) y en Jaén, poblado de Castellones de Céal (Hinojares), en época ibérica, a partir de la aparición de lastres de red hechos de plomo (Mayoral et al. 2000:185-197). Por nuestra parte, tenemos evidencias concretas de la práctica de esta actividad: ya que en Alarcos hemos localizado restos de barbo (Barbus barbus) y de bivalvos fluviales de dos especies diferentes. Aunque sería una actividad margi- nal, los oretanos practicaron la pesca y sobre todo el marisqueo fluvial, a juzgar por la gran cantidad de moluscos bivalvos, que constituyen casi la totalidad de la muestra (97\%), compuesta por 229 restos $(\mathrm{NR}=229)$, representativos de un mínimo de 72 individuos $(\mathrm{NMI}=72)^{4}$. Pertenecen a dos de las cuatro especies autóctonas de bivalvos de agua dulce de la Cuenca del Guadiana, Potomida littoralis y Unio delphinus. Creemos que estos bivalvos tendrían un interés bromatológico ocasional, ya que la cercanía del 
curso del Guadiana al yacimiento permite plantear la explotación de estos moluscos solo como un complemento ocasional en la dieta, quizá en épocas de hambruna o escasez ya que las ná- yades, al contrario que los bivalvos marinos, se caracterizan por tener un sabor y olor poco agradables, además de por la dureza de su carne (García Quiroga 2009).

\begin{tabular}{|c|c|c|c|c|c|c|c|}
\hline TAXÓN & $\begin{array}{l}\text { Número de Restos } \\
\text { Identificables } \\
\text { (NRI) }\end{array}$ & $\begin{array}{c}\% \text { sobre NRI } \\
\text { DE sU GRUPO } \\
\text { (229) }\end{array}$ & $\begin{array}{c}\text { \% sobre NRI DEL } \\
\text { TOTAL } \\
\text { (Domésticos/salvajes/ } \\
\text { Acuáticos) } \\
(5935)\end{array}$ & $\begin{array}{l}\text { Número Minimo de } \\
\text { individuos } \\
\text { (NMI) }\end{array}$ & $\begin{array}{c}\% \text { sobre NMI } \\
\text { DE sU GRUPO } \\
\text { (73) }\end{array}$ & $\begin{array}{l}\% \text { sobre NMI } \\
\text { DEL TOTAL } \\
\text { (249) }\end{array}$ & $\begin{array}{c}\text { Senil } \\
\text { Adultos } \\
\text { Juveniles } \\
\text { Infantiles }\end{array}$ \\
\hline \multicolumn{8}{|c|}{$\begin{array}{c}\text { GRUPO } 3 \\
\text { ANIMALES ACUÁTICOS }\end{array}$} \\
\hline $\begin{array}{l}\text { Barbus barbus } \\
\text { Barbo }\end{array}$ & 1 & 0,43 & 0.016 & 1 & 1,36 & 0.40 & Indet \\
\hline $\begin{array}{l}\text { Potomida littoralis } \\
\text { Náyade/ almeja de rio }\end{array}$ & 100 & 43,6 & 1,68 & 32 & 43,83 & 12,85 & Indet \\
\hline $\begin{array}{l}\text { Unio delphinus } \\
\text { Náyade/ almeja de rio }\end{array}$ & 128 & 55,8 & 2,16 & 40 & 54,79 & 16,0 & Indet \\
\hline $\begin{array}{l}\text { TOTAL ACUATICOS } \\
\text { SOBRE NRI }\end{array}$ & 229 & $100 \%$ & 3,86 & 73 & $100 \%$ & $29,31 \%$ & \\
\hline
\end{tabular}

Figura 8. Animales acuáticos

\subsection{La preparación de la carne y el uso de los recursos animales}

En los restos óseos procedentes de Alarcos se han detectado gran cantidad de marcas de corte y descarnado en ovicápridos, bóvidos o suidos, que aportan datos relativos al tratamiento y preparación de la carne como alimento. En muchos casos se trata de trazos finos pero profundos producidos por herramientas metálicas usadas tanto para cortar como para fracturar. Algunas de estas marcas indican claramente tratamientos de desollado, desarticulación, descarnado y la posterior fracturación del hueso para poder consumir la médula, lo que implica un intenso aprovechamiento de los animales. Entre las alteraciones antrópicas llama la atención el bajo número de huesos quemados que, además, presentan un grado de cremación muy bajo, lo que indica una escasa exposición al fuego. Ello ha favorecido la escasa fragmentación de las muestras, ya que la acción del fuego tiende a aumentarla.

\begin{tabular}{|c|c|c|c|c|c|c|c|c|}
\hline \multirow[b]{2}{*}{$\begin{array}{l}\text { Total Número de Restos } \\
\text { Identificables (NRI) }\end{array}$} & \multirow{2}{*}{\begin{tabular}{c} 
NÚMERO \\
\multirow{2}{5}{5935}
\end{tabular}} & \multicolumn{2}{|l|}{ PORCENTAJE } & \multicolumn{2}{|l|}{$\begin{array}{l}\text { Total NÚMERO DE RESTOS } \\
\text { IDENTIFICABLES (NRI) }\end{array}$} & \multicolumn{3}{|c|}{ TOTAL EDADES } \\
\hline & & $51,2 \%$ & & 249 & $\begin{array}{l}\text { Senil } \\
\text { Adulto }\end{array}$ & $\begin{array}{l}8 \\
135\end{array}$ & $\begin{array}{l}\text { Juveniles } \\
\text { Infantiles }\end{array}$ & $\begin{array}{l}23 \\
10\end{array}$ \\
\hline $\begin{array}{l}\text { Total determinados solo por } \\
\text { su tamaño (NRD-T) }\end{array}$ & 3189 & $27,4 \%$ & $\begin{array}{l}\text { Especies grandes: } 1396 \\
\text { Especies medianas: } 55 \\
\text { Especies pequeñas: } 1738\end{array}$ & & & & & \\
\hline Total NRI + NRD-T & 9124 & $78,6 \%$ & & & & & & \\
\hline Total indeterminados & 2471 & $21,4 \%$ & & & & & & \\
\hline Total número de restos (NR) & 11595 & $100 \%$ & & 249 & & & & \\
\hline
\end{tabular}

Figura 9. Animales documentados

\begin{tabular}{|c|c|c|c|c|c|c|c|c|}
\hline \multirow[b]{2}{*}{$\begin{array}{l}\text { Total Número de Restos } \\
\text { Identificables (NRI) }\end{array}$} & \multirow{2}{*}{$\begin{array}{c}\text { NÚMERO } \\
5935\end{array}$} & \multicolumn{2}{|l|}{ PORCENTAJE } & \multicolumn{2}{|l|}{$\begin{array}{l}\text { Total NUMMERO DE RESTOS } \\
\text { IDENTIFICABLES (NRI) }\end{array}$} & \multicolumn{3}{|c|}{ TOTAL EDADES } \\
\hline & & $51,2 \%$ & & 249 & $\begin{array}{l}\text { Senil } \\
\text { Adulto }\end{array}$ & $\begin{array}{l}8 \\
135\end{array}$ & $\begin{array}{l}\text { Juveniles } \\
\text { Infantiles }\end{array}$ & $\begin{array}{l}23 \\
10\end{array}$ \\
\hline $\begin{array}{l}\text { Total determinados solo por } \\
\text { su tamaño (NRD-T) }\end{array}$ & 3189 & $27,4 \%$ & $\begin{array}{l}\text { Especies grandes: } 1396 \\
\text { Especies medianas: } 55 \\
\text { Especies pequeñas: } 1738\end{array}$ & & & & & \\
\hline Total NRI + NRD-T & 9124 & $78,6 \%$ & & & & & & \\
\hline Total indeterminados & 2471 & $21,4 \%$ & & & & & & \\
\hline Total número de restos (NR) & 11595 & $100 \%$ & & 249 & & & & \\
\hline
\end{tabular}

Figura 10. Especies salvajes y domésticas 
La ganadería era un recurso importante pero, como ya hemos señalado, no solo para el consumo de carne. Al estudiar los patrones de edad se observa el predominio de los individuos adultos, especialmente en bóvidos y ovejas, a tenor de los datos de los estudios sobre nuestra fauna ${ }^{4}$. Sólo en los suidos y en la cabra hay una relativa mayor representación de los individuos juveniles o infantiles, que en conjunto constituyen casi un $30 \%$ de los individuos representados. Los íberos, como la mayoría de los pueblos de la antigüedad, aprovechaban sus recursos de forma intensiva, caso del ganado (fuerza de tracción, leche, sangre, lana, piel astas, estiércol, etc.), de ahí que el sacrificio solo se lleve a cabo generalmente cuando el animal es adulto. Así, la explotación cárnica de bóvidos y ovejas infantiles o juveniles es minoritaria. En este punto, debemos recordar que la oveja aporta más litros de leche por unidad que la cabra. En definitiva, la abundancia de adultos indica que los animales fueron utilizados para la obtención de productos secundarios.

Igualmente, parece que el sacrificio y consumo de la carne de los animales domésticos responde a un patrón de estacionalidad. Según se desprende de las edades de muerte de ciertos animales infantiles y juveniles, así como la de algunos adultos jóvenes, sabemos que el sacrificio de los ovicápridos se producía en dos fases básicamente: primavera -desde mediados de abril hasta junio-, sacrificándose en esta fase principalmente individuos infantiles o subadultos de un año. El segundo momento en el que se documentan sacrificios de animales es el otoño y comienzos del invierno, cuando se sacrificarían individuos jóvenes con el primer molar emergiendo y otros de más edad con el segundo o tercer molar en el mismo proceso. En el caso de otras estaciones sólo en un caso se ha documentado el sacrificio de un individuo en verano. Recordemos que a principios-mediados del verano se cosechan los cereales y generalmente tendrían abundantes recursos vegetales que consumir. Los datos disponibles para otros animales son escasos. Algunos suidos parece que fueron sacrificados durante la transición primavera-verano, con un año aproximadamente; también se documen$\tan$ otros que fueron matados sobre los tres años y medio, concretamente durante el otoño, por lo que tendríamos unos procesos similares a los descritos en los ovicápridos. Entre los bóvidos hay individuos, sobre todo adultos, consumidos en primavera.

En definitiva, entre los diversos grupos de edad del conjunto encontramos ocho seniles, ciento treinta y cinco adultos, veintitrés juveniles y solo diez infantiles

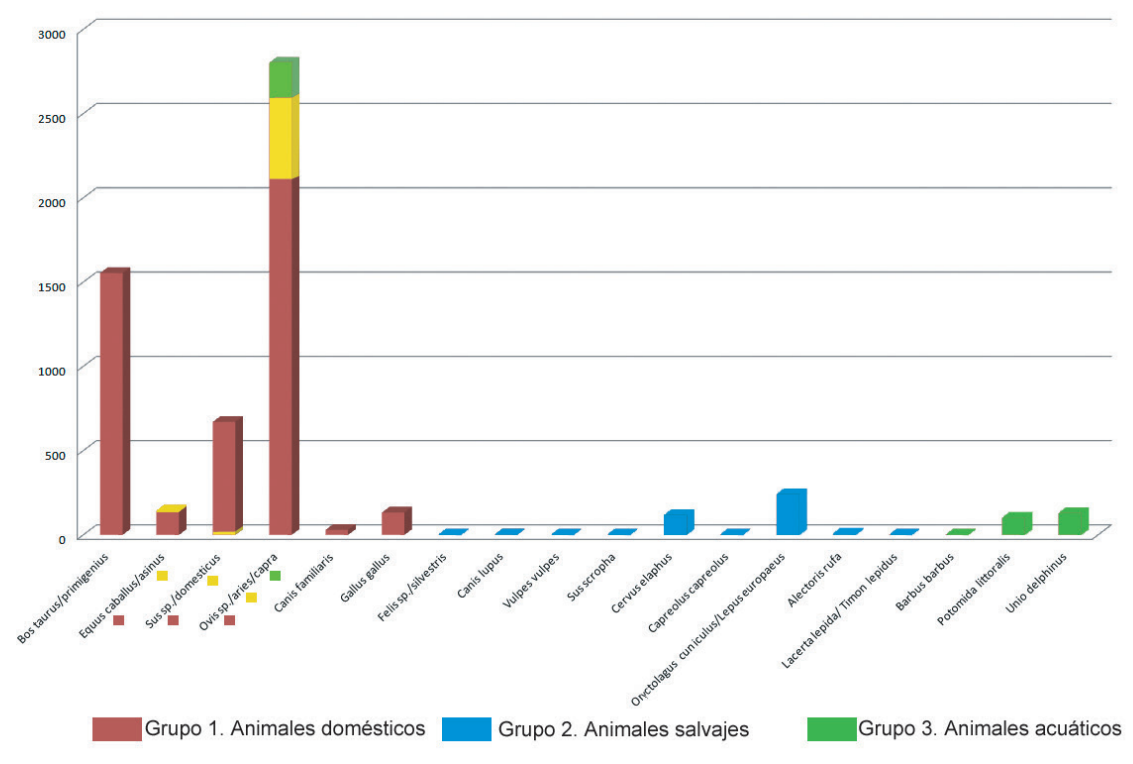

Figura 11. Representación de los diferentes tipos de animales 


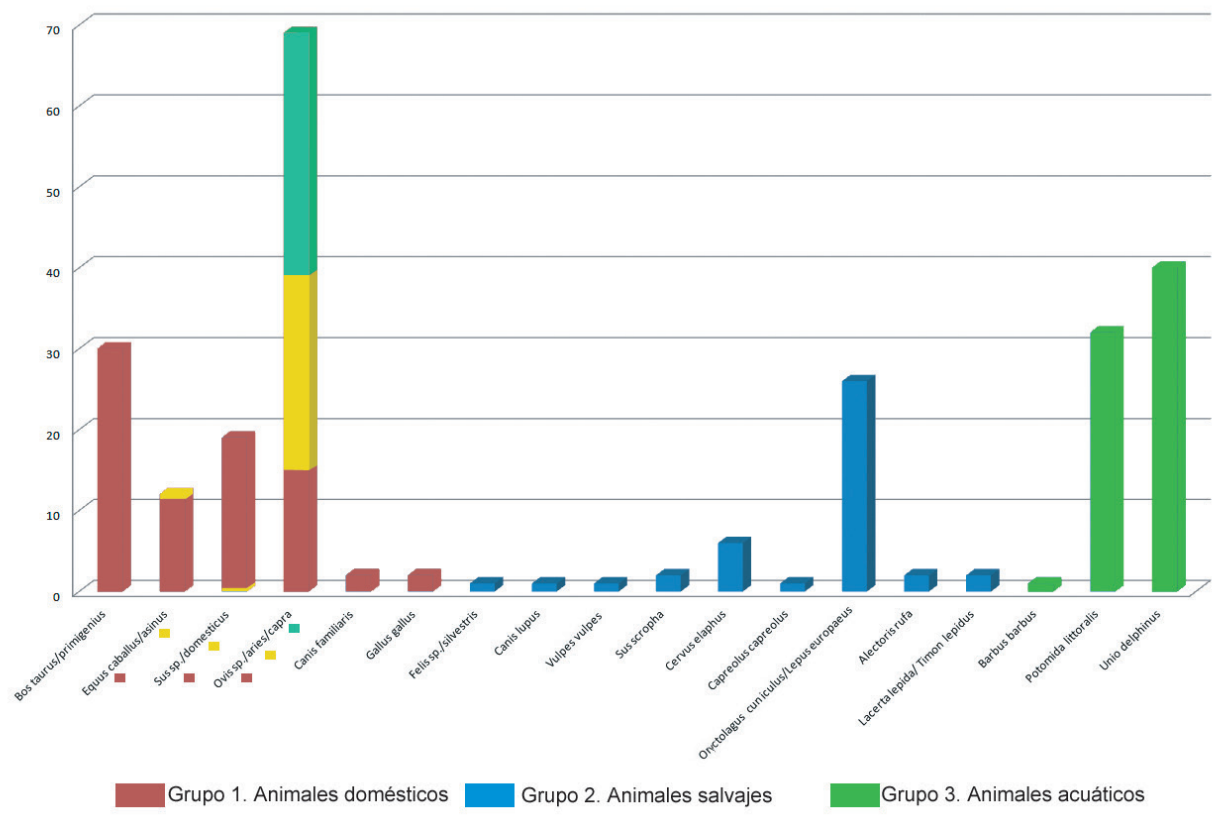

Figura 12. Número mínino de individuos identificados

\subsection{Otros recursos animales}

Además de la sal, un recurso utilizado para la conservación de alimentos, en concreto fruta, fue la miel (Ciarallo 2004; Juan y Matamala 2005: 240). A lo largo de la Prehistoria y Protohistoria la miel ha tenido diversos usos: medicinal, cosmético, ritual, protección contra la corrosión, elaboración de pinturas, adhesivo, agente aislante, elaboración de bebidas como hidromiel y otras de carácter alcohólico o iluminación (Evershed et al. 1997; McGovern et al. 2013). En la península ibérica los datos más antiguos sobre el uso de la miel los proporciona la pintura levantina con la escena de la recolección de miel de la cueva de la Araña (Bicorp, Valencia) (Aparicio et al. 2007) y los restos de esta sustancia detectados en una vasija del dolmen de Azután (Toledo) y en otra procedente de la necrópolis de Valle de las Higueras (Huecas, Toledo) (Bueno et al. 2007: 58).

Otro de los productos de la apicultura es la cera, muy rica en vitamina A y con propiedades antioxidantes. Un estudio reciente sobre más de 6.000 vasijas de cerámica prehistóricas de yacimientos de Oriente Próximo, Europa y del norte de África (Roffet-Salque et al. 2015) ha reconocido residuos de cera de abejas en cerámicas neolíticas, por lo que la explotación de este producto $\mathrm{y}$, por tanto, la cría de las abejas melíferas se remonta al menos a esta época.
En territorio peninsular, el primer testimonio de cera de abeja lo proporciona un cuenco campaniforme de La Calzadilla (Almenara de Adaja, Valladolid) de la segunda mitad del III milenio (Brezmes et al. 2013: 331). A partir de aquí se ha identificado este producto en asentamientos de cronología diferente, desde la Edad del Bronce a época ibérica, y en todos ellos su aparición se produce tanto en contextos domésticos como rituales y funerarios (Sánchez y Cañabate 1997; Sánchez Moreno 2005; Sánchez et al. 2011). De la actividad apícola de los iberos deja constancia escrita Estrabón (Geograph. III, 2,6) al mencionar la miel y la cera de abeja de la Turdetania como productos de calidad. A nivel arqueológico, la primera ha sido reconocida a partir de la documentación de colmenas cerámicas localizadas en los territorios correspondientes a la antigua Edetal TSM y la ciudad de Kelin (Bonet y Mata 1995) en el área valenciana, y también en diversos yacimientos de La Manchuela albacetense (Soria 1999).

En el ámbito oretano no se conocen colmenas, pues seguramente fueron confeccionadas con materiales perecederos, sin embargo, los análisis de contenidos realizados sobre recipientes cerámicos de Alarcos confirman la práctica de la apicultura. En el interior de un recipiente de Alarcos se ha identificado residuo de cera de abeja en muy alta proporción, lo 
que aboga como se ha señalado anteriormente, por su empleo como combustible para iluminación, aunque no descartamos que evidencie la presencia de miel.

En la Grecia clásica el empleo de la cera, entre otros usos, se vinculaba a la iluminación nocturna, en determinados actos sociales como el simposio o banquete (Foxhall 2007: 92-93). En el mundo ibérico, aunque se ha propuesto el seguimiento de los ritmos diurnos (Luzón 1973: 37), la cera de abeja pudo emplearse ocasionalmente en la iluminación artificial. Las lucernas, a diferencia de otros recipientes de importación, no fueron imitadas por los ceramistas iberos por lo que se ha sugerido la utilización de otros recipientes, como pequeños cuencos de cerámica común, como lámparas. En este sentido, el hallazgo en santuarios bastetanos de cuencos de bordes entrantes quemados se ha asociado con la función de lámparas o lucernas (Sánchez Moreno 2005: 69-70).

\section{Conclusiones}

La caracterización de cualquier sociedad o grupo cultural resulta incompleto si no tenemos presente los sistemas productivos empleados para asegurar su desarrollo. Éstos pueden estar diseñados para alcanzar un nivel básico de subsistencia o, si se ha logrado un cierto grado de complejidad, para obtener recursos excedentarios con los que configurar un sistema de intercambios comerciales. Hasta fechas relativamente recientes nuestro conocimiento sobre las características de los procesos productivos de los pueblos prerromanos peninsulares era bastante desigual y fragmentario, por lo que era frecuente recurrir al empleo de "lugares comunes" a la hora de tratar la economía en el mundo ibérico, resaltando, lógicamente, la preponderancia de las actividades agropecuarias, básicamente agrícolas, que se verían complementadas por otras prácticas como la caza y la recolección. En líneas generales, se presentaba un panorama que parecía muy cercano a una economía de subsistencia poco compleja.

El desarrollo de campañas sistemáticas de excavación arqueológica en importantes yacimientos ibéricos, sobre todo desde los años 80 del pasado siglo, empezó a aportar un rico y variado elenco de materiales arqueológicos, entre los que destacaban un número cada vez mayor de objetos de importación, presencia que no encajaba con el carácter de subsisten- cia atribuido, de forma genérica, a la economía de algunos pueblos íberos. La aplicación de nuevas técnicas de análisis y el desarrollo de estudios antracológicos, arqueobotánicos, etc... nos está posibilitando presentar una imagen más acertada de los sistemas productivos de los pueblos prerromanos peninsulares y está corroborando que su modelo económico era más complejo del que en un principio se creía, especialmente entre los grupos ibéricos situados más al interior. Esta realidad nos permite comprender mejor la existencia de un poblamiento jerarquizado, pensado para desarrollar una estrategia de control y explotación de un territorio, organizada desde los oppida oretanos, que generarán un sistema productivo basado en un concepto dual: por un lado, asegurar la subsistencia a partir de una agricultura cerealista complementada por productos ganaderos $y$, por otra parte, generar excedentes agrarios y mineros con los que poder desarrollar intercambios que permitiesen a la elites acceder a bienes de prestigio importados.

Los datos arqueobotánicos corroboran la especialización agrícola de los pueblos oretanos, que se centrarán esencialmente en la producción de los trigos desnudos y la cebada vestida, jugando un papel secundario otras producciones como los trigos vestidos. Junto a los cereales se desarrolla el cultivo de frutales, como almendros, ciruelos, cerezos/guindos, higueras, granados, posiblemente olivo y vid y de leguminosas, entre las que se han documentado lentejas, habas, guisantes, guijas y yero. Junto a estas especies, cuya presencia se explica por la acción antrópica, también podemos comentar la presencia en los alrededores de los poblados oretanos de especies que definirían un entorno forestal de relativa densidad, más bien tendente a un paisaje de dehesa, en el que destacarían las quercáceas y los pinos, que permitirían su aprovechamiento para la obtención de madera para la construcción, leña para hogares y hornos y productos como bellotas y piñones. La inmensa mayoría de los asentamientos oretanos se encuentran muy próximos a recursos hídricos, especialmente ríos, junto a los cuales se desarrollarían especies de ribera como fresnos y sauces, de los que también se aprovecharía su madera como recurso constructivo y para la elaboración de productos artesanales.

En la producción ganadera, en líneas generales, se confirma el predominio de los ovicápridos y bóvidos, seguidos de los suidos, 
confirmando noticias apuntadas desde hace décadas (Chapa 1981: 156-157). En los análisis de restos de fauna, una de las constantes que se repiten es el predominio de animales domésticos respecto a los salvajes. El aporte a la dieta de la carne de caza es muy reducido en relación a la carne obtenida de la cabaña ganadera. Es un hecho probado que la práctica de la actividad cinegética, además de su componente social, también servía para completar el aprovisionamiento de carne, pieles y otros subproductos. Esta actividad, además de en el registro óseo, está documentada en escenas pintadas en vasos cerámicos, en donde aparecen representados entre otros, jabalíes, ciervos, cabras montesas y zorros.

Todos estos procesos productivos provocaron una transformación del paisaje, aún en una fase poco desarrollada, pero en la que ya empiezan a hacerse presentes los efectos de una incipiente antropización del entorno, especialmente en las zonas más próximas a los principales poblados oretanos, donde la explotación del medio natural sería más intensa y, en cierto modo, prefiguraría la posterior estrategia de control económico del medio desarrollada por los romanos.

Por otro lado, el control económico del paisaje favoreció un dinamismo comercial que comenzó a experimentar el territorio objeto de nuestro estudio desde comienzos del I milenio a.C. y se consolidará a partir del siglo VI a.C. La clara jerarquización que se aprecia en el poblamiento de la Oretania Septentrional revela un sistema bien organizado por las jefaturas, ubicadas en los principales oppida, con el fin de asegurarse la obtención de excedentes en materias primas (agrarias, mineras, sal,....) con los que comerciar y lograr a cambio preciados bienes que refuercen su prestigio.

\section{Notas}

1. Los análisis antracológicos y carpológicos de las campañas de excavación de 2004, 2005 y 2010 han sido realizados por Guillem Pérez Jordà y Yolanda Carrión Marco de la Universidad de Valencia.

2. Alberto Sánchez Vizcaíno, David Jesús Parras Guijarro, José Alfonso Tuñón López y Bautista Ceprián del Castillo, del Instituto de Arqueología Ibérica, han realizado análisis de contenidos mediante GC-MS y HPLC-MS, sobre siete recipientes cerámicos de Alarcos, cuyos resultados incluimos en este trabajo.

3. La fauna estudiada procede de la excavación del horno ibérico de este yacimiento que fue realizada por nosotros en 1999.

4. Según el Informe de Bárbara Avezuela Aristu sobre la malacofauna de los niveles ibéricos y medievales del yacimiento de Alarcos (Ciudad Real). Campañas 2010, 2011 y 2102.

5. Yravedra Sainz de los Terreros; J. (Inédito): La fauna de mamíferos del yacimiento arqueológico de Alarcos (Ciudad Real) en sus niveles ibéricos. Alarcos 2001-2005.

\section{Bibliografía}

AA.VV. (1999): Els productes alimentaris d' origen vegetal a l'Edat del Ferro de l'Europa Occidental: de la producció al consum. Actes del XXII Col. loqui Internacional per a l' Estudi de l'Edat del Ferro. Sèrie Monogràfica 18, Girona (1998).

Alonso i Martínez, N. (1999): De la llavor a la farina. Processos agrícoles protohistorics a la Catalunya Occidental. Monographies d'Archéologie Méditerranéenne, 4, Lattes.

Aguelo, X.; Palomo, A.; Pons, O.; de Juan, C. (2008): El pecio de Binissafúller. En Pérez Ballester, J. y Pascual, G. (eds). V Jornadas de Arqueología Subacuática.), Valencia: 199-207.

Aparicio, J., Mesado, N., Morote, J.G.; Ros, J. (2007): Catálogo de la Comunidad Valenciana. Catálogo del Arte Prehistórico de la Península Ibérica y de la España Insular. Arte Rupestre Levantino, Aragón, Cataluña, Cuenca, Albacete, Guadalajara, Andalucía, Comunidad Valenciana y Murcia, Real Academia de Cultura Valenciana. Serie Arqueológica, 22 (I): 253-368.

Bernabeu Auban, J.; Bonet Rosado, H.; Mata Parreño, C. (1987): Hipótesis sobre la organización del territorio edetano en época ibérica plena: el ejemplo del territorio de Edeta/Llíria. Iberos. Actas de las I Jornadas sobre el Mundo Ibérico, Jaén (1985): 137-156.

Blánquez, J. (ed.) (1995): El Mundo Ibérico: Una nueva imagen en el año 2000. JCCM, Toledo.

Bonet Rosado, H.; Mata Parreño, C. (1995): Testimonios de apicultura en época ibérica. Verdolay, 7, Murcia: 277-285. 
Brezmes Escribano, M. A.; García Vázquez, I.; Martín Vela, R. (2013): Hidromiel en contextos de la Antigüedad. Actas de las III Jornadas de Jóvenes Investigadores del Valle del Duero. Salamanca: 323-338.

Broncano Rodríguez, S. y Blánquez Pérez, J. (1985): El Amarejo. E.A.E., 139. Madrid.

Broncano, S. (1989): El depósito votivo ibérico de El Amarejo. Bonete (Albacete). E.A.E., 156. Madrid.

Bueno, P., Barroso, R., de Balbín, R., 2007: “Agricultores y metalúrgicos”. En Pereira, J. (coord.): Prehistoria y Protohistoria de la Meseta Sur (Castilla-La Mancha). Ciudad Real: 57-94.

Carricondo Sánchez, J.F; Sánchez Zarca M.T.; Vaquero A. (2008): Relevancia paleontológica del yacimiento de troncos fósiles silicificados de plantas vasculares en la comarca manchega de Alcázar de San Juan. Patrimonio Geológico y Paleontológico de Alcázar de San Juan. Tesela, 34, Ciudad Real: 3-55.

Cerdeño Serrano, M. L.; Pérez De Inestrosa, L. (1992): La explotación de sal en época celtibérica en la región de Sigüenza (España). Actes du Colloque Intemational du sel. Salies-de-Béarn: 167-175.

Ciarallo, A. (2004): Il vetro e la conservazione degli alimenti. Vitrum. Il vetro fra arte e scienza nel mondo romano (Beretta M.; Di Pasquale, G., eds.), Firenze: 87-93.

Costa, M.; Morla, C.; Sainz,H. (eds.) (1997): Los bosques ibéricos. Una interpretación geobotánica. Ed. Planeta.

Cuadrado Díaz, E. (1987): La necrópolis ibérica de El Cigarralejo (Mula, Murcia). Bibliotheca Praehistórica Hispana, 23, Madrid.

Chapa Brunet, T. (1981): El toro androcéfalo de Balazote: nueva puesta a punto de su problemática. $A l-B a-$ sit, 10: 145- 157.

Chapa Brunet, T. y Mayoral Herrera, V. (2007): Arqueología del trabajo. El ciclo de la vida en un poblado ibérico. Akal. Madrid.

Charrouf, Z.; Guillaume, D. (2008): Argain oil: occurrence, composition and impact on human health. European Journal of Lipid Science and Technology. 110: 632-636.

Esteban Borrajo, G., Hevia Gómez P., Pérez Avilés, J.J., Vélez Rivas, J. (2003): La Transición del Bronce Final a la Primera Edad del Hierro en el Cerro de Las Cabezas (Valdepeñas-Ciudad Real). Cuadernos de Estudios Manchegos, 25-26: 11-46.

Evershed, R.P., Vaughan, S. J., Dudd, S.N.; Soles, J. S. (1997): Fuel for thought? Beeswax in lamps and conical cups from the late Minoan Crete. Antiquity, 71: 979-985.

Fernández Rodríguez, M. (2009): Sistemas de almacenamiento en Alarcos: el ejemplo del edificio tripartito. En García Huerta, R. y Rodriguez, D. (eds): Sistemas de almacenamiento entre los pueblos prerromanos peninsulares. Ediciones de Universidad de Castilla-la Mancha. Cuenca: 225-240

Fíguls, A.; Weller, O.; Grandia, F.; Bonache, J.; González, J.; Lanaspa, R.M. (2013): La primera explotación minera de la sal gema: la Val salina de Cardona (Cataluña, España), Chungara, Revista de Antropología Chilena, 45, 1: 177-195.

Foxhall, L. (2007): Olive Cultivation in Ancient Greece: Seeking the Ancient Economy. Oxford University Press, Oxford; New York.

García Huerta, R. y Morales, F.J. (2009): “Almacenamiento, tratamiento y conservación de alimentos en los pueblos ibéricos de la meseta meridional”. En García Huerta, R. y Rodríguez, D.: Sistemas de almacenamiento entre los pueblos prerromanos peninsulares. Ediciones de Universidad de Castilla-la Mancha. Cuenca:167-208.

García Quiroga, F. (2009): Cita de una nueva población de la náyade (Unio cf pictorum), en el río Moros a su paso por el municipio de Vegas de Matute (Segovia), $M+A$. Revista de Medio Ambiente, 6: 68-84.

García Rodríguez, M.P.; Pérez González, M.E. (2007): Suelos salinos en la cuenca del río Cigüela (cuenca alta del Guadiana). Revista de la Asociación Española de Teledetección, 27: 53-58.

Gracia Alonso, F. (1995): Producción y comercio del cereal en el NE de la Península Ibérica entre los siglos VI-TI a. C. Pyrenae, 26, Barcelona: 91-113

Iborra Eres, M.P. (2000): Los recursos ganaderos en época ibérica. En Mata Parreño C. y Pérez Jordá, G. Saguntum: Papeles del Laboratorio de Arqueología de Valencia, $\mathrm{n}^{\circ}$ Extra 3, 2000 (Ejemplar dedicado a: Ibers. Agricultors, artesans i comerciants. III ${ }^{a}$ Reunió sobre Economia en el Món Ibèric): 81-92.

Iborra Eres, M.P. (2004): La ganadería y la caza desde el bronce final hasta el ibérico final en el territorio valenciano. Diputación de Valencia, Valencia.

Juan Tresserras, J.; Matamala, J.C. (2005): Estudio de residuos microscópicos y compuestos orgánicos en utillaje de molido y análisis de contenido de vasijas cerámicas, En P. Bueno; R. Balbín de; R. Barroso: El dolmen de Azután (Toledo). Áreas de habitación y áreas funerarias en la cuenca interior del Tajo. Universidad de Alcalá de Henares, Diputación de Toledo, Monografías 02, Toledo: 235-241. 
Ladero Quesada, M. A. (1987): La renta de la sal en la Corona de Castilla (siglos XIII-XVI). Homenaje al Prof. Juan Torres Fontes I, Murcia: 821-838.

López, J.A. y Alba, F. (2009): Ecología, etnobotánica y etnofarmacología del argán (Argania spinosa). Boletín Latinoamericano y del Caribe de Plantas Medicinales y Aromáticas, 8: 323-341.

Luzón Nogué, J. M. (1973): Excavaciones en Itálica. Estratigrafía en el Pajar del Artillo (Campaña 1970). Excavaciones Arqueológicas en España, 78, Madrid.

Mata Parreño, C. (coord.) (2014): Fauna ibérica: de lo real a lo imaginario. Serie de Trabajos Varios 117. Museu de Prehistòria de València. València.

Mata Parreño, C.; Pérez Jordà, G. (eds.) (2000): Ibers. Agricultors, artesans i comerciants. III ${ }^{a}$ Reunió sobre Economia en el Món Ibèric. Saguntum Extra-3, Valencia (1999).

Mata Parreño, C.; Pérez Jordà, G.; Vives-Ferrándiz Sánchez, J. (eds.) (2010): De la cuina a la taula. IV Reunió d'Economia en el primer mil·lenni aC. Saguntum Extra-9, Valencia.

Mata,C.; Badal,E.; Collado;E.; Ripollés, P.P. (eds.) (2010): Flora Ibérica. De lo real a lo imaginario. Serie Trabajos Varios del Servicio de Investigación Prehistórica, 111. Valencia.

Mayoral, V., Chapa, Ma .T., Pereira, J. y Madrigal, A. (2000): "La pesca fluvial como recurso económico en época ibérica tardía: un ejemplo procedente de Los Castellones de Céal (Hinojares, Jaén)", Trabajos de Prehistoria, 57 (1): 185-197.

McGovern, P.; Luley, B.; Rovira, N.; Mirzoian, A.; Callahan. M.; Smith, K.; Gretchen R.; Davidson, T.; Henki, J.M. (2013): Beginning of viniculture in France. Proceedings of the National Academy of Sciences of the United Sattes of America, vol. 110, 25:10147-10152.

Miret, M., Sanmartí, J., Santacana, J. (1984): Distribución espacial de núcleos ibéricos: un ejemplo en el litoral catalán. Arqueología Espacial, IV, Teruel: 173-186.

Peña-Chocarro, L.;Zapata,L.; González,J.E.; Ibañez,J.J. (2000): Agricultura, alimentación, y uso del combustible: Aplicación de modelos etnográficos en arqueobotánica. Saguntum Extra, 3, Valencia: 403-420.

Pereira, J. (2010): Paleoetnografía del consumo de bellotas en las comunidades prerromanas peninsulares. En Bueno,P.; Gilman,A.; Martin,C.; Sanchez-Palencia,J.J. (eds.) Arqueología, Sociedad, Territorio y Paisaje. Homenaje a $M^{a}$ Dolores Fernandez-Posse. C.S.I.C.: 279-290.

Pérez Jordá, G.; Alonso Martínez, N.; Iborra Eres, M.P. (2007): Agricultura y ganadería protohistóricas en la Península Ibérica: modelos de gestión. En Rodríguez Díaz, A.; Pavón Soldevila, I. (coords.) Arqueología de la Tierra. Paisajes rurales de la protohistoria peninsular. Universidad de Extremadura, Cáceres: 327-372.

Pérez Jordà, G.; Iborra, Ma P.; Grau Almero, E.; Bonet Rosado, H.; Mata Parreño, C. (2000): La explotación agraria del territorio en época ibérica: los casos de Edeta y Kelin, XXII Col-loqui Internacional per l'Estudi de l'Edat del Ferro, Sèrie Monogràfica 18, Girona (1999): 151-167.

Roffet-Salque, M.; Regert M.; Evershed R.P.; Outram A.K.; Cramp, L.J.; Decavallas, O.; Dunne, J.; Gerbault, P.; Mileto, S.; Mirabaud, S.; Pääkkönen, M.; Smyth, J.; Šoberl, L.; Whelton, H.L.; Alday-Ruiz, A.; Asplund, H.; Bartkowiak, M.; Bayer-Niemeier, E; Belhouchet, L; Bernardini, F.; Budja M.; Cooney, G.; Cubas, M.; Danaher, E.M.; Diniz, M. et al. (2015): Widespread exploitation of the honeybee by early Neolithic farmers. Nature, 2, 527(7577), London: 226-230.

Rodríguez, D. y López-Menchero, V. (2009): Caracterización tipológica y funcional de molinos rotatorios y de vaivén asociados a un edificio de almacenamiento agrícola: Alarcos Sector III. En García Huerta, R. y Rodriguez, D.: Sistemas de almacenamiento entre los pueblos prerromanos peninsulares. Ediciones de Universidad de Castilla-la Mancha. Cuenca: 209-224.

Ruiz Rodríguez, A.; Molinos Molinos, M. (1984): Elementos para un estudio del patrón de asentamiento en las campiñas del Alto Guadalquivir durante el Horizonte Pleno Ibérico (un caso de sociedad agrícola con Estado). Arqueología Espacial, IV, Teruel:187-206

Ruiz Rodríguez, A.; Molinos Molinos, M. (1993): Los iberos: análisis arqueológico de un proceso histórico. Crítica, Barcelona.

Salinas de Frías, M. (1986-1987): Indigenismo y romanización de Carpetania: Observaciones en torno al proceso romanizador en la Meseta meridional. Studia historica. Historia antigua, 4-5: 27-36.

Sánchez Moreno, A. (2005): "Santuarios ibéricos en la Bastetania". Arqueología y Territorio, 2: 65-80.

Sánchez Vizcaíno, A.; Cañabate Guerrero, M.L. (1997): Identificación de grasas y ésteres de ceras en recipientes arqueológicos. Caesaraugusta, 73: 319-325. 
Sánchez Vizcaíno, A.; Parras, D.; Ramos, N. (2011): Análisis químico de contenidos en recipientes cerámicos", en C. Rueda, Territorio, culto e iconografía en los santuarios iberos del Alto Guadalquivir (ss. IV a.n.e.-I d.n.e). Caaiberica, Textos CAAI n ${ }^{\circ}$ 3, Universidad de Jaén, Jaén: 221-226.

Soria Combadiera, L. (2000): Evidencias de producción de miel en la comarca del Júcar (Albacete) en época ibérica. Saguntum Extra-3, Valencia (1999): 177-180.

Tarradell i Mateu, M. (dir.) (1968): I Reunión de Historia de la Economía Antigua de la Península Ibérica. Barcelona

Uroz Sáez, J.; Poveda Navarro, A. M.; Muñoz Ojeda, F. J.; Uroz Rodríguez, H. (2007): El departamento 86: Una taberna del barrio industrial ibérico de Libisosa (Lezuza, Albacete). Arqueología de Castilla-La Mancha. Actas de las I Jornadas (Millán, J. M. y Rodríguez, C. (coords.), Cuenca (2005): 143-170.

Vallejo Sánchez, J. I.; Córdoba Alonso, I.; Niveau de Villedary, A. M. (1999): Factorías de salazones en la bahía gaditana: economía y organización espacial. XXIV Congreso Nacional de Arqueología, vol.3. Cartagena (1997): 107-114.

Vélez, J.; Pérez Aviles, J.J. y Torres,T. (2013):Almacenes y graneros. Tras la recogida de la producción agrícola había que almacenarla y conservarla...Orisos,2. Valdepeñas, Ciudad Real: 103-149.

Vila Valenti, J. (1955): Notas sobre la antigua producción y comercio de la sal en el Mediterráneo Occidental. I Congreso de Arqueología del Marruecos español. Tetuán, (1953-1954): 225-234.

Yravedra Sainz de los Terreros; J. (Inédito): La fauna de mamíferos del yacimiento arqueológico de Alarcos (Ciudad Real) en sus niveles ibéricos. Alarcos 2001-2005.

\section{Fuentes clásicas:}

Cayo Plinio Segundo: Naturalis Historia.

Estrabón: Geografía de Iberia, trad. de J. Gómez Espelosín, Alianza Editorial, Madrid 2007.

Lucio Junio Moderato Columela: De re Rustica, Los doce Libros de Agricultura, trad. de V. Tinajero, Madrid 1879. 